\title{
Portable Anti-bedsore System
}

\author{
Ping Shi*, Weimin Wang and Hongliu Yu \\ Institute of Rehabilitation Engineering and Technology, School of Medical Instrument and Food Engineering, University of \\ Shanghai for Science and Technology, Shanghai, P.R.China \\ ${ }^{*}$ Corresponding author
}

\begin{abstract}
The purpose of this paper is to develop a portable anti-bedsore system. This portable anti-bedsore system, which can provide a new way to the prevention and treatment of bedsore. This above way not only suitable for bedridden patients also for long-term wheelchair users. MCS-51 was applied in the hardware of the system, which was used in the vibration motor groups control. Vibration motor groups which act on the sensitive parts all over the body. Its aim is to achieve the effects of the bedsore prevention and treatment by improving blood circulation and preventing users' muscle atrophy. The portable anti-bedsore device has the advantages of rational structure, comfortable effect, small volume, low cost and is easy to carry. According to the different working modes of motor groups, it could provide a new solution for reducing the incidence rate and relieve the pain of illness for bedridden patients and wheelchair users. Therefore this device deserves to be popularized.
\end{abstract}

\section{Keywords—bedsore; vibration; cure; prevention; portable}

\section{INTRODUCTION}

Bedsore continue to be a common health problem, particularly among the physically limited or bedridden elderly[1]. The problem exists within the entire health framework, including hospitals, clinics, long-term care facilities and private homes. Bedsore also known as pressure ulcers or pressures, which on the affected area leads to poor blood circulation and eventually contributes to cell death, skin break down, and the development of an open wound[2]. Bedsore cause a great deal of suffering and frustration to patients, their relatives and caregivers. They also increase the workload of the health care professionals and health care cost drastically. Therefore, bedsore prevention becomes an important issue in the field of rehabilitation engineering. Currently, turning-over bed and anti-bedsore mattress are popular in treatment and prevention bedsore. Turning-over bed, which was mainly applied in hospital, is bulky and expensive. The anti-bedsore mattress is easily available and relatively cheap. However, anti-bedsore mattress, which usually has singleness mode, user-unfriendly interface without fault alarm and requires external supply. Both of them are not suitable for applying in small areas such as wheelchair seats or parts of the body. Prevention and treatment of bedsore from almost anywhere at any time, which is necessary for long-term wheelchair users. In this paper, a portable bedsore prevention system is designed for those patients.

\section{Design of Portable Anti-Bedsore System}

\section{A. Design Consideration}

MCS-51 was used as the controller in main control system of the anti-bedsore system. Vibration motor controlled by
MCS-51 were designed to $6 \times 4$ matrix[3].The pressure that between user and portable anti-bedsore device could be changed by vibration of the motors. The above method could improve blood circulation and prevent users' muscle atrophy, and achieve the effects of the bedsore prevention and treatment According to some disadvantages of existing devices in the market, the portable anti-bedsore system was presented in this paper. This design had one obvious advantage in applying portable control system. The control system consisted of the single-chip module, the power module, the display module, the keyboard module, the driver module and the vibration motor groups. The system block diagram was shown in Figure I.

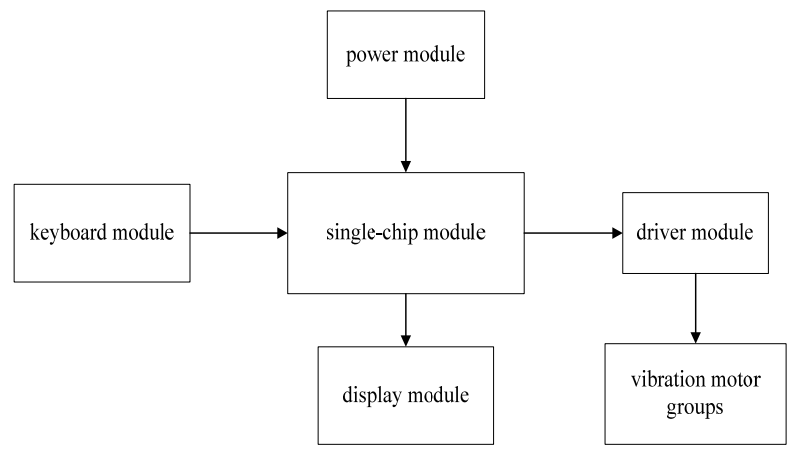

FIGURE I. BLOCK DIAGRAM OF THE PORTABLE ANTI-BEDSORE SYSTEM

1) Mechanical system:

Portable anti-bedsore device was surrounded by hard plastics. It consisted of vibration motor groups and LCD (organic light-emitting diode) display module. Vibration sub-system consisted of motor groups and cotton cushion. The LCD display module, the circuit board, the leakage protector, and the rechargeable battery were installed on the side panel. The portable anti-bedsore device was 50 centimeters long and 30 centimeters wide. The top view was shown in Figure II, and the side view was shown in Figure III.

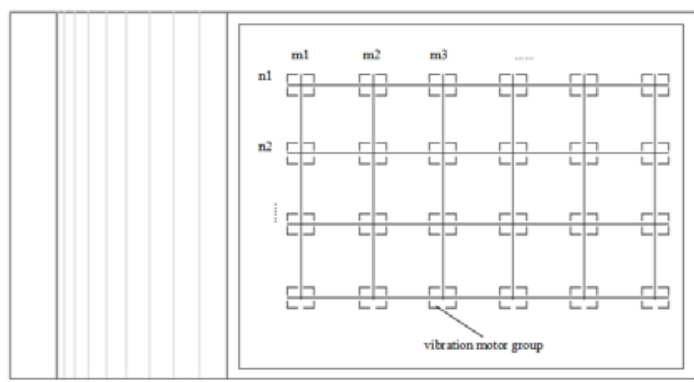

FIGURE II. TOP VIEW OF PORTABLE ANTI-BEDSORE DEVICE 


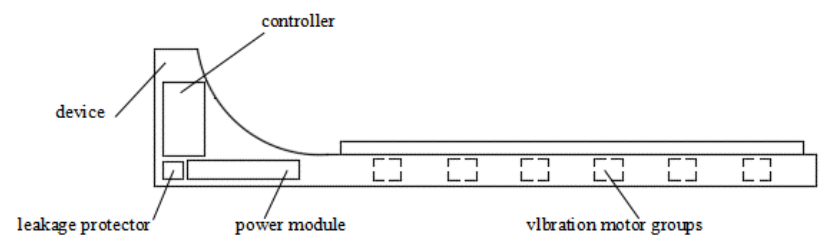

FIGURE III. SIDE VIEW OF PORTABLE ANTI-BEDSORE DEVICE

\section{2) Electronic system:}

Vibration motor groups which were fixed on the device are controlled by MCS-51. They could work in different vibration modes and different vibration intensities. The work flowchart was shown in Figure IV. The portable anti-bedsore system adopted STC-12C5A60S2 as CPU[4]. The main part of the vibration adopted $6 \times 4$ matrix motor groups, which could provide different working ways for users. The first working mode was matrix motor groups working follow the sequence number under the control of MCU. The second working mode was all of motors work together. The device could also meet the users' individual needs. Vibration motor groups, vibration modes, vibration intensities and vibration time could be selected by users. In addition, Portable anti-bedsore system could also keep the same working mode after breaking off with suspend function. This method could achieve a better effect of prevention and treatment on the body or body parts.

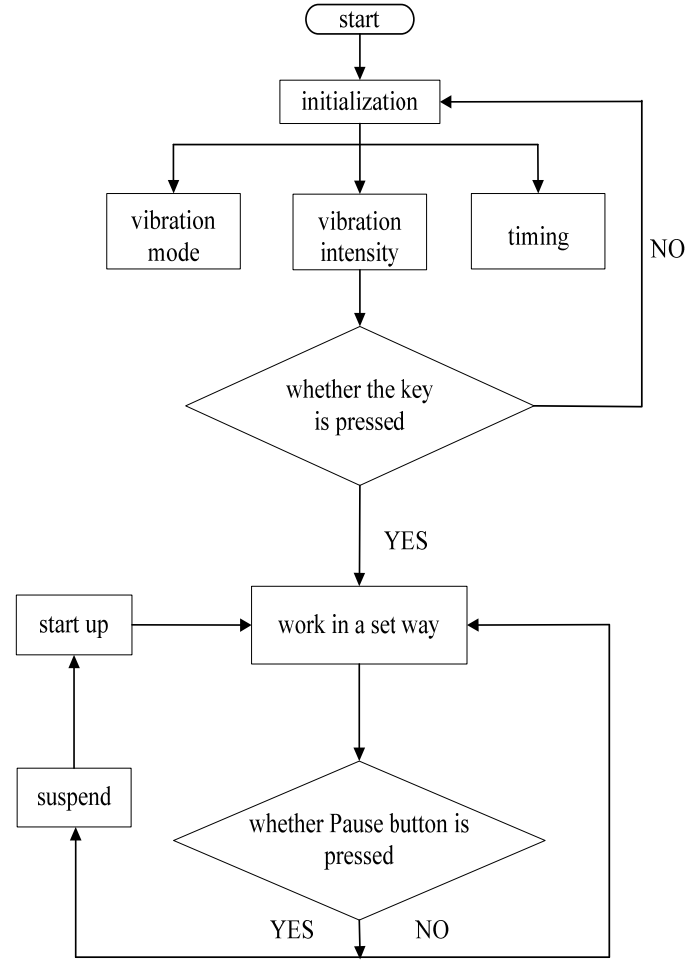

FIGURE IV. WORKING FLOWCHART OF PORTABLE ANTI-BEDSORE DEVICE

\section{B. Control Module Design}

L298n motor driver was used this design. MCS-51 operates on very low voltage and current while the motors require higher voltages and current. Therefore, the MCS-51 cannot provide them such higher current. Motor driver is a little current amplifier[5]. The internal schematic diagram of L298n was shown in Figure V.

The L298 is an integrated monolithic circuit in a 15-lead Multi watt and PowerSO20 packages. It takes a low current signal and gives out a high current signal which can drive a motor. Its maximum supply voltage is $46 \mathrm{~V}$ and maximum output DC current is $4 \mathrm{~A}$. It is a high voltage, high current dual full-bridge driver designed to accept standard TTL logic levels. L298 consists of four independent power amplifiers. Four inputs are provided to the four power amplifiers of 1298 . There are also four outputs[6]. The design use push buttons and whenever specific push button is pressed, specific motor will start running. The Motor drive module was shown in Figure VI, and the principle diagram of motor control was shown in Figure VII.

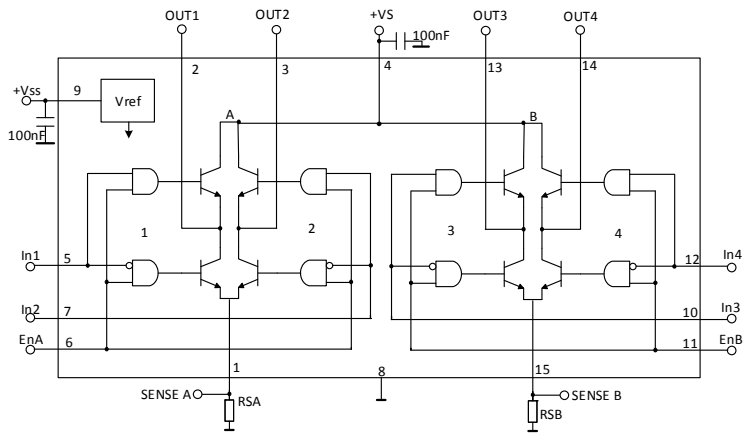

FIGURE V. INTERNAL SCHEMATIC DIAGRAM OF L298

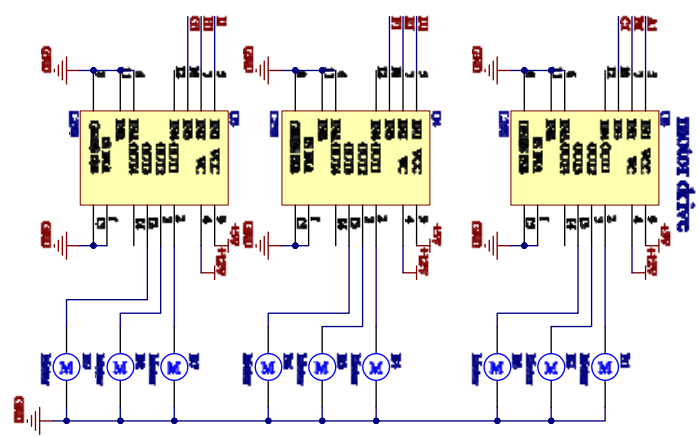

FIGURE VI. MOTOR DRIVE MODULE

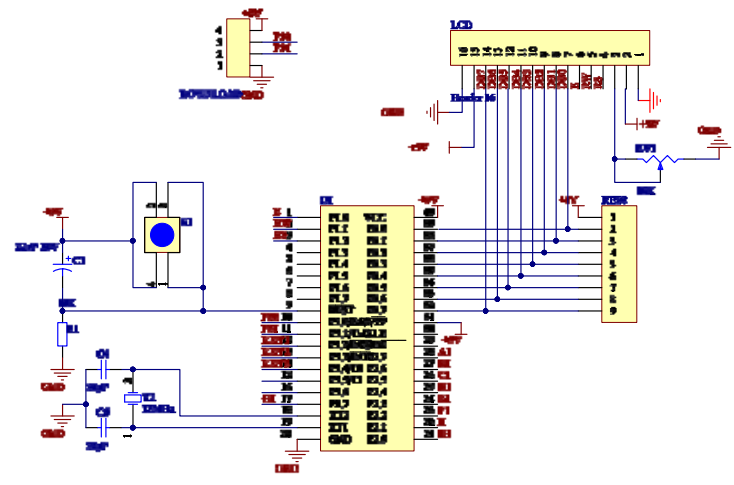

FIGURE VII. PRINCIPLE DIAGRAM OF MOTOR CONTROL 


\section{STC12C5A60S2 Single Chip Timer/Counter}

STC12C5A60S2 is a single-chip Microcontroller based on a high performance 1t architecture 80C51 CPU, which is produced by STC MCU limited. It has four timers. Timer 0 and Timer 1 are like the ones in the conventional 8051, both of them can be individually configured as timers or event counters Timer 0 and timer 1 have four operating modes from which to select. The "timer" or "counter" function is selected by control bits $\mathrm{c} / \mathrm{t}$ in the special function register TMOD. The timer/counter have four operating modes, which are selected by bit-pairs $(\mathrm{m} 1, \mathrm{~m} 0)$ in TMOD[7]. The design of portable anti-bedsore system adopted Timer 1 to produce PWM pulse[8].

\section{Pulse Width Modulator (PWM)}

Pulse width modulation (PWM) technique is a common and popular speed control technique[9]. Where the power delivered to the load is determined by the duty ratio of pulsating output waveform. The on and off Periods are rapid so the average power delivered to output is low compared to other methods. DC motors in particular, are very responsive to PWM. They adjust their speed with little lag time after receiving a PWM signal. And PWM signals are very fast, especially when few or no computations are required. Motor responsiveness and innate PWM speed combine to make PWM controllers extremely efficient. In this paper, we used pulse width modulation technique for controlling the speed of matrix motor groups, as is a popular and reliable method. The flow chart of PWM output was shown in Figure VIII.

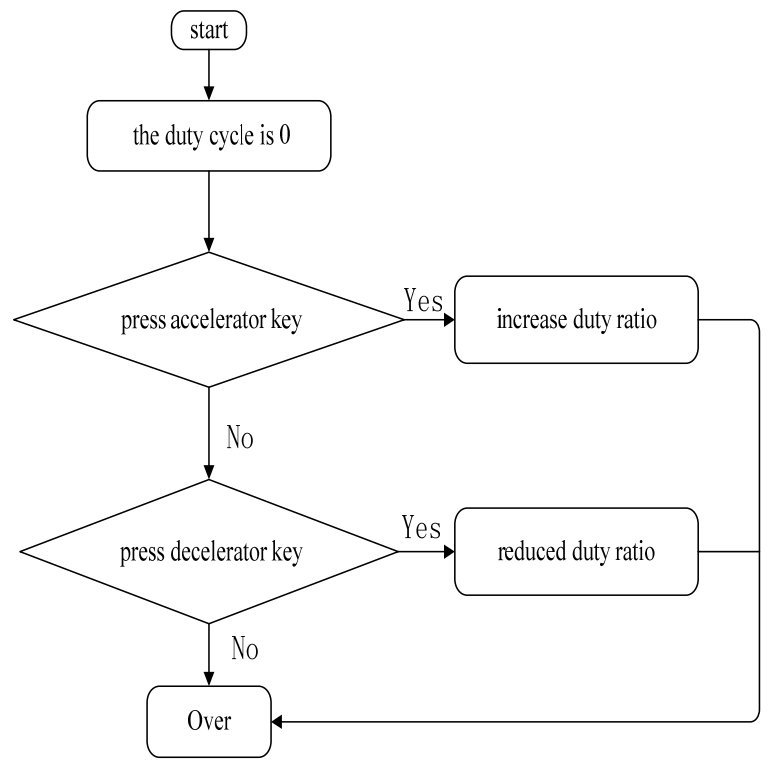

FIGURE VIII. FLOW CHART OF PWM OUTPUT

\section{E. Key Control Module Design}

There are two ways that could respond to key-down events, i.e. external interruption and inquiry way[10]. This design of portable anti-bedsore system chose the way of external interruption to respond in key-down events. The schematic diagram of keys was shown in Figure IX.
The corresponding bits of the keys were set to 1 while they are pressed, and set to 0 while they are not pressed. The variation of the corresponding bits can be used to judge whether the keys were pressed or not.

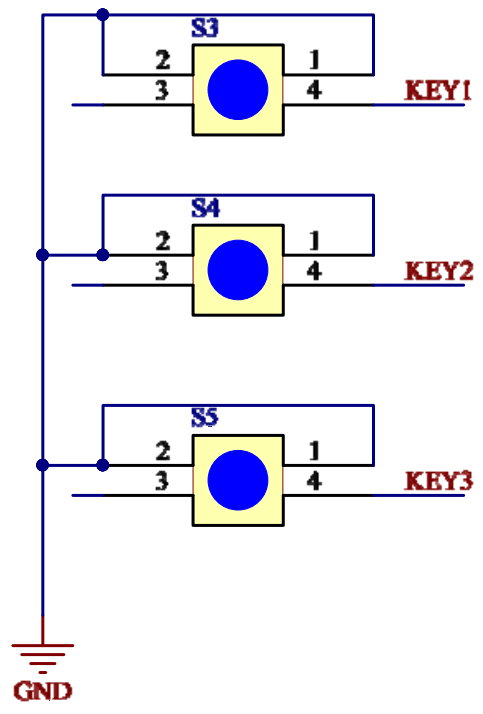

FIGURE IX. SCHEMATIC DIAGRAM OF KEYS

\section{Display Module}

LCD1602, i.e., 1602 character-type liquid crystal display, is a kind of dot matrix module to display letters, numbers, characters and so on. It is composed of $5 \times 7$ or $5 \times 11$ dot matrix positions. Each position can display one character. There is a dot pitch between two characters and a space between lines, thus separating characters and lines. The model 1602 means it displays 2 lines of 16 characters. 1602 LCD module of reading and writing, and the screen and light mark operation operations are through the instructions of programming realize[11].

\section{SUMMARY}

With the development of society, more and more humane and intelligent medical products were developed and applied. Rehabilitation equipment should also be developed in the direction of "Portable, humanity, family orientation", which meet health requirements of patients in various levels. Portable anti-bedsore system was introduced in this paper and has the advantages of simple structure, convenient operation, safe and reliable. This design of portable anti-bedsore system provides a better method to reduce the incidence of bedsore and to improve patient's quality of life. Meanwhile, it has certain social value and commercial prospects.

\section{REFERENCES}

[1] Jaul E. Assessment and management of pressure ulcers in the elderly: current strategies.[J]. Drugs \& Aging, 2010, 27(4):311.

[2] Bhattacharya S, Mishra R K. Pressure ulcers: Current understanding and newer modalities of treatment.[J]. Indian Journal of Plastic Surgery Official Publication of the Association of Plastic Surgeons of India, 2015, 48(1):4.

[3] Song Z. Design of Stepping Motor Control System Based on MCS-51[J] Journal of Changjiang Engineering Vocational College, 2007. 
[4] Shi Y C, Wang X C, Yin-Yin W U, et al. A Design Based on STC12 Microcontroller for Anti-falling Elevator System[J]. Value Engineering, 2017.

[5] Paul D. Design and Fabrication of a De Driver Circuit Control Dc Motor[J]. 2014, 2(1):1.

[6] Song J. PWM Speed Regulator for DC Motor based on L298[J]. Journal of Weifang University, 2004.

[7] STC12C5A60S2 is a single-chip Microcontroller based on a high performance $1 \mathrm{t}$ architecture $80 \mathrm{C} 51 \mathrm{CPU}$,

[8] Kazmierkowski M P, Malesani L. Current control techniques for three-phase voltage-source PWM converters: a survey[J]. IEEE Transactions on Industrial Electronics, 2002, 45(5):691-703.

[9] Rząsa J, Supronowicz H. Comparison of pulse width modulation methods used in matrix converter control[J]. Archives of Electrical Engineering, 2003, 52(4):421-445.

[10] He J. MCS-51 SCM External Interrupt Repeat Response Catch and Timing Analysis[J]. Computer Study, 2010.

[11] Zheng R J, Jia X L, Cui H L, et al. Simulation of LCD1602 Display Drived by Single Chip Microcomputer Fictious Serial Port[J]. Journal of Hebei Engineering \& Technical College, 2010. 